\title{
A face reconhecível do medo: domesticação e redenção do monstro animal em $O$ Exorcista ${ }^{1}$
}

Marcia Heloisa Amarante Gonçalves (UFF)

Recebido 9 set. 2013/Aprovado 22 abr. 2014

\section{Resumo}

Este artigo analisa a função das características animais na transformação de humano para monstruoso no filme $\boldsymbol{O}$ Exorcista, baseado no best-seller homônimo de William Peter Blatty. Lançado em 1973, o filme permanece uma das realizações mais perturbadoras do cinema de horror, bem como uma obra seminal do subgênero demoníaco. As narrativas de horror descrevem uma jornada na qual o animal, em virtude de sua presença ubíqua em nossas vidas, frequentemente atua como um psicopompo. Embora a representação da animalidade como marca de vilania tenha sido nociva a nossa percepção de alguns animais, ela não obstante contribuiu para a reflexão sobre a relação homem-animal. As narrativas de horror permanecem o espaço fundamental da animalidade nas obras de ficção por sua capacidade de reunir representações arquetípicas, convidando leitor/ espectador a experimentar um confronto vicário com medos reprimidos. Este artigo propõe uma reflexão sobre a animalidade como via de reintegração do Eu, defendendo a permanência dos monstros animais no horror.

Palavras-chave: Animalidade; monstruosidade; domesticação; psicopompo.

\footnotetext{
1 Este trabalho é um recorte de minha pesquisa de doutorado em literatura comparada - "Guia sombrio da alma: o monstro como psicopompo no horror moderno" -, em andamento na UFF, sob a orientação da Profa. Dra. Sonia Torres, com bolsa do CNPq.
} 
O horror, mais do que qualquer outro gênero literário e cinematográfico, descreve uma trajetória na qual o animal está sempre presente. A insistência deste fascínio garantiu um lugar de memória para o animal na ficção. Graças ao seu hipnótico apelo visual, o cinema de horror impõe-se como espaço definitivo desse acervo. Catártico e inquietante, sujeita o espectador a uma experiência vicária de confronto com a sua própria represa de temores.

O presente artigo busca examinar a função dos atributos animais utilizados na construção do ser humano como monstro em $O$ Exorcista, filme norte-americano de William Friedkin, com roteiro assinado por William Peter Blatty, baseado em seu livro homônimo. Lançado em 1973, o filme permanece até hoje uma das realizações mais perturbadoras do cinema e figura como obra seminal do ciclo de horror demoníaco predominante na década de 1970. Este ciclo resgatou a obsessão gótica pela fé - ou a falta dela - sugerindo que ciência e civilização não eram suficientes para salvaguardar o ser humano da ameaça de degeneração física e moral, de retorno a um estado primitivo no qual a fronteira entre humanidade e animalidade parecia desaparecer.

Na trama de O Exorcista, Chris MacNeil, uma jovem atriz divorciada, vê-se forçada a recorrer a um padre jesuíta quando a suposta enfermidade que acometeu a sua filha de doze anos atinge o máximo de sua gravidade e, apesar de sua convicção ateísta, ela começa a suspeitar de uma possessão demoníaca. O padre Karras é um homem em conflito que está contemplando a possibilidade de deixar o sacerdócio. Carente de uma prova da existência de Deus, ele reencontra a sua fé na presença do demônio. Enquanto acompanhamos a degeneração de Regan, outrora uma criança saudável e amorosa, testemunhamos o tour de force emocional de sua mãe e do padre Karras, ambos convictos de que a única chance de sobrevivência da menina está na supremacia de Jesus Cristo sobre Satã. Para ajudá-los a libertar corpo e alma de Regan, o experiente padre Merrin é convocado. No fim, Regan é salva pelo sacrifício dos dois padres, que morrem no processo.

Fiel à incerteza que marca o limiar do fantástico, a trama retarda o reconhecimento da possessão demoníaca e os personagens só contemplam o sobrenatural após o esgotamento de possibilidades médicas e psiquiátricas, na busca pelo diagnóstico do que desconfiam ser uma doença com características psicossomáticas. A força coercitiva da manifestação monstruosa obriga-os a reconhecer a sua ignorância factual perante acontecimentos que evadem parâmetros dedutivos e lógicos. O Exorcista oferece a possibilidade de avaliar a possessão como tema arcaizante em uma narrativa urbana na qual a manutenção da ordem social e o imperativo da lógica estabelecem ciência e religião como árbitros de progresso. Os personagens recorrem a rituais medievais e medidas apotropáicas para conter e combater um mal que sabem anacrônico. Uma vez que a vítima torna-se animalesca e

Niterói, n. 35, p. 83-96, 2. sem. 2013 
monstruosa, a fé no Cristianismo é a arma eleita para libertá-la, resgatando assim a sua humanidade. Ainda que livro e filme contribuam para o reforço negativo da animalidade como signo do mal, ambos reiteram a relevância da função medianeira do monstro animal no processo de individuação do ser humano.

A atual pesquisa foi dividida em três temas: a natureza demoníaca do monstro animal, o feminino monstruoso e o animal como psicopompo. Busco propor uma reflexão sobre o reconhecimento da animalidade como via de reintegração da personalidade fragmentada, defendendo assim a permanência do monstro animal nas narrativas de horror.

\section{A natureza demoníaca do monstro animal}

Em nossa nostalgia por imagens totêmicas, agrada-nos reverenciar o animal como entidade desprovida de qualquer semelhança conosco, enquanto alimentamos, simultaneamente, o medo despertado por sua desconcertante familiaridade.

O vínculo entre possessão demoníaca e animalidade encontra na Bíblia um dos seus episódios mais memoráveis. De acordo com os evangelhos do Novo Testamento, Jesus libertou um homem de uma legião de demônios transpondo os espíritos malignos do corpo da vítima para uma vara de porcos. Os animais, possuídos, atiraram-se no mar. Blatty usa o seguinte trecho, do Evangelho de Lucas, como epígrafe em O Exorcista:

E quando [Jesus] pisou em terra firme, teve com um homem da cidade que estava possuído por demônios... Diversas vezes o acometeram e ele foi acorrentado... mas ele tornava a romper os grilhões ... Jesus perguntou: "Qual é o seu nome?" E ele respondeu: “Legião”. (BLATTY, 2007, trad. livre)

Em $O$ Exorcista, a ameaça satânica é simbolizada por representações de animalidade monstruosa. No livro, a outrora angelical Regan exibe um comportamento despudoradamente antissocial, bem como dá vazão a sua animalidade com episódios regulares de miados, latidos, uivos, relinchos e grunhidos. No filme, a animalidade aparece escamoteada em cenas que induzem o espectador à náusea; secreções, fluidos corporais, urina e vômito são acompanhados pela fala do demônio, que se refere constantemente à Regan como "a porca".

A recorrência de imagens bestiais permanece entretecida em um dos temas centrais da narrativa: domesticação. A palavra, cuja etimologia remete ao latim domus (casa) é bastante pertinente para o presente trabalho. Em primeiro lugar, $O$ Exorcista é um pesadelo doméstico, centrado no confinamento do lar da família MacNeil. Em segundo lugar, a derradeira esperança para restaurar a normalidade é um exorcismo (uma forma de domesticação), desempenhado pelo padre Damien - cujo próprio nome significa "domar", em grego. E, em terceiro lugar, como proponho 
2 Ampliando ainda mais o conceito de domus, poderíamos argumentar que $O$ Exorcista é uma batalha por alojamento e hospedagem: o demônio invade o lar e o corpo da criança. Ele deseja tornar-se o senhor (dominus) dos dois lugares, sobretudo por ser uma casa sem uma figura masculina de autoridade (a ausência do pai) e um corpo sem a benção dos sacramentos (a ausência do Pai). interpretar o confronto final do padre com o demônio como um adestramento, a domesticação desempenha um papel ainda mais abrangente, uma vez que sugere o sacrifício como garantia de desfecho satisfatório. ${ }^{2}$

Os animais compõem o núcleo da transformação monstruosa de Regan. Embora os exorcistas não consigam definir a identidade do demônio que possuiu a menina, eles não têm dúvidas a respeito de sua animalidade. A impossibilidade de categorizar o demônio, mas, não obstante, reconhecê-lo como animalesco, está no cerne da alteridade monstruosa. $\mathrm{O}$ monstro tradicionalmente é aquilo que percebemos como não-humano, apartado da graça de Deus por não ter sido criado a Sua imagem. O bicho-papão, que atormenta o imaginário infantil, nada mais é do que uma expressão popular da arcaica fera devoradora que agrega em sua voracidade duas desconfortáveis certezas humanas: a da morte e a da consciência de ser carne. Em seu ensaio sobre a versão restaurada do filme, Michael Arnzen defende a presença do animal como parte inalienável da caracterização do monstro demoníaco:

Imagens animais aparecem ao longo de todas as versões de O Exorcista, desde a estátua semelhante a um pássaro do demônio Pazuzu até os sons animalescos produzidos por Regan em seu quarto. A própria trilha sonora utiliza sons reais de animais para sugerir a presença do demônio. Pazuzu se refere frequentemente a Regan como a "porca", alinhando retoricamente o corpo feminino pubescente com o suíno. (ARNZEN, 2011, p. 365, trad. livre)

A figura eleita como epítome desta ameaça, sobretudo no filme, é o demônio assírio-babilônico Pazuzu, o rei dos demônios do vento, que como senhor do vento sudeste é tradicionalmente associado a doenças, pragas e catástrofes naturais. Um híbrido homem-animal com dois pares de asas, ele possui corpo de homem, mas cabeça de cão, garras de águia, cauda de escorpião e um falo em forma de serpente. Semelhante à iconografia católica do Diabo, a figura de Pazuzu mescla elementos humanos e animais para tornar-se mais poderosa e assustadora.

Arnzen alega que a possessão demoníaca, tal como apresentada em $O$ Exorcista, busca 'demonizar o feminino' (ARNZEN, 2011, p.263). Eu diria que ela vai além e animaliza o humano, ilustrando um dos trunfos mais poderosos do demônio para insultar o possuído e aqueles que testemunham a sua condição aflitiva. A ideia de que qualquer comparação entre humano e animal tende a ser vista como degradante está tão enraizada na mentalidade cristã ocidental que nem mesmo os céticos conseguem abstraí-la. Chris MacNeil pode não acreditar em Deus ou no diabo, mas sente medo e repulsa ao testemunhar sua filha grunhindo e sendo chamada de "porca" e "suína". Kathryn Shevelow, em seu livro sobre o advento do movimento de proteção animal, aponta que "o emprego de analogias animalescas à guisa de insulto de- 
monstra, com exemplos negativos, o desejo de manter distinções absolutas entre seres humanos e animais: as pessoas sentem que é degradante, até mesmo cruel, serem comparadas a um bicho" (SHEVELOW, 2008, p. 102, trad. livre). O sujeito animalizado paira precariamente no limiar da esfera da apreensão racional, tornando-se algo que não conseguimos mais compreender, capturar ou deter. Na ausência da classificação, não há controle possível. $\mathrm{O}$ monstro, enquanto defeito ou falha da normalidade, é amiúde caracterizado por um corpo não-humano para realçar ainda mais o apagamento dos limites. Regan, a menina, deixa uma rosa no prato da mãe todo dia no café da manhã. Regan, a porca, esvazia os intestinos ruidosamente e vomita nas visitas. Ao que parece, $\mathrm{o}$ demônio investe em um conjunto sonoro e performático para atestar que a humanidade está fora da esfera de proteção do Criador.

A ideia da infância como um período imaculado de pecados é subvertida pela conversão da menina em agente corruptor; o seu corpo, outrora reduto inviolável, é invadido e modificado. Regan regride a um estado animalesco que não atenta para a força coercitiva das limitações morais e desconhece os interditos inibitórios que regulam a experiência do ser humano em sociedade. Para o autor, o objetivo principal do demônio é atacar a condição humana do possuído, tornando-o igualmente besta. A escolha de uma criança explicita a intenção de forma ainda mais contundente, imprimindo uma sexualidade lasciva e um comportamento obsceno à virgindade de um corpo pré-pubescente.

O diretor William Friedkin optou por não acentuar a animalidade de Regan nas telas em sua versão original (1976), mas duas cenas restauradas incluídas na Version You've Never Seen (2000), acentuam a natureza bestial da possessão demoníaca. A primeira é a famosa 'cena da aranha', na qual uma acrobática Regan desce as escadas contorcida como uma aranha gigante. Friedkin alegou que o motivo pelo qual a cena foi cortada na primeira versão foi puramente técnico: os cabos que seguravam o corpo da atriz (a contorcionista Linda Hager, que serviu de dublê para Linda Blair nesta cena) não puderam ser apagados na edição. Arnzen, todavia, especula:

[...]o corpo humano é apresentado de forma animalesca, movendo-se de quatro, transgredindo assim a distinção repressiva entre o humano e o animal sobre a qual se ampara boa parte da sociedade "civilizada". O fato de Regan ser capaz de contorcer o seu corpo de maneira não-humana e descer a escada de costas reforça esta noção de transgressão pela inversão, tornando a cena, ao mesmo tempo, bestial e estranhamente humana". (ARNZEN, 2011, p.366, trad. livre)

O corpo possuído é, ao mesmo tempo, território invadido e foco de resistência. A cena da aranha reforça a anomalia da coabitação de corpos antagônicos, mas potencializa Regan fisicamente. No entanto, do mesmo modo em que o monstro animal faculta 
o relaxamento das repressões, ele mescla pulsão de vida com pulsão de morte. Assim, Regan é um animal investido de libido, mas a sua própria condição monstruosa sugere o seu inevitável aniquilamento.

A outra cena restaurada, mais filosófica do que visual, é uma conversa entre padre Karras e padre Merrin, na qual Merrin explica ao jovem Karras que "o objetivo da possessão" é "nos levar ao desespero; a rejeitar nossa própria humanidade, Damien: nos vermos animalescos, vis, putrefatos; sem dignidade; grotescos; desprezíveis". (BLATTY, 2007, p. 335, trad. livre)

O conceito de animais como indignos e desprezíveis está associado às religiões abraâmicas. Embora as serpentes sejam as mais difamadas, cães e porcos habitam a mesma zona marginal de impureza. Ainda conservamos certa ambiguidade em relação aos porcos (os reconhecemos como seres sencientes, mas não questionamos a violência do seu abate), mas os cães garantiram uma condição privilegiada como animal doméstico favorito. No entanto, nem sempre foi assim, como recorda Kathryn Shevelow:

\begin{abstract}
Antigamente, os moralistas cristãos agrupavam cães e porcos juntos como as criaturas mais sórdidas de todas, carniceiros nojentos que possuíam vícios como concupiscência e gula. Dizia-se que cães comiam o próprio vômito. Manter animais domésticos era uma ameaça particularmente perigosa ao limite a ser preservado entre o humano e o bestial (SHEVELOW, 2008, p.63, trad. .livre).
\end{abstract}

Em seu estudo sobre os animais na Bíblia, o autor Michael Bright afirma que os cães, mencionados quarenta vezes na Sagrada Escritura, geralmente são citados com "nada mais do que desdém". Ele assim resume a visão bíblica sobre os cães: "Não chegavam a ocupar o patamar mais baixo, pois esta honra era reservada ao porco, mas chegavam bem perto" (BRIGHT, 2006, p. 112, trad. livre). Regan, quando possuída, dialoga tanto com o pit bull quanto com o porco em uma incômoda construção de animalidade monstruosa que se sustenta, em grande parte, amparada pelo nosso preconceito em relação a ambos. Cães e porcos têm em comum traços como inteligência e predisposição para o convívio com seres humanos, mas também atuam como padrão para animais sem etiqueta. Em seu artigo sobre mensagens subliminares em $O$ Exorcista, Wilson Bryan Key discute as relações simbólicas entre porcos e seres humanos: “O porco, ao menos para o homem moderno, foi repudiado por ter maus modos que enfatizam a sua imundície, ganância, gula e letargia". (KEY, 1977, p. 111, trad. livre)

Talvez a mais poética e inequívoca referência a Regan como um animal esteja no fim do romance quando, perdendo a luta pela sobrevivência da menina, o padre Karras relembra um episódio de sua infância: a morte do seu amado cão, Reggie (cujo próprio nome assemelha-se a Regan). O trecho sobrepõe cão e menina, 
ressaltando a condição enferma e moribunda de ambos com palavras como "esquelético", "febril", "vomitando", "dose/injeção":

Então uma recordação da infância surgiu melancólica, uma lembrança de Reggie, o seu cão vira-lata, cada vez mais esquelético e entorpecido no seu precário apartamento; Reggie tremendo, febril, vomitando enquanto Karras tentava cobri-lo com toalhas, esforçando-se para que tomasse um pouco de leite morno, até que um vizinho apareceu, olhou para Reggie e, meneando a cabeça, disse: "O seu cachorro está com cinomose. Precisa de uma dose de remédio na veia, urgente".

O demônio. Aos gritos.

"O seu cachorro precisa de uma dose na veia urgente"

Karras levantou-se imediatamente e voltou para o quarto de Regan, onde a conteve em seus braços enquanto Sharon administrava uma injeção de Librium [...]. (BLATTY, 2007, p.312, trad. livre)

A morte de Reggie, o cão, funciona como um arcabouço moral para os atuais conflitos internos de Karras: impotência e culpa. Um espectro de negligência também parece assombrá-lo, uma vez que ele acredita que a sua incapacidade de ser um filho mais dedicado pode ter causado a morte de sua mãe e o seu posterior distanciamento da Igreja. O espelhamento do cão morto na criança doente é o que, finalmente, desperta Karras para a sua responsabilidade com Regan. Ele precisa vencer, apesar de medicina, psiquiatria e até mesmo a Igreja tradicional - personificada pelo lacônico e idoso exorcista, padre Merrin - terem fracassado. Assim como Reggie era o seu cão, Regan é a sua paciente. $O$ fardo não pode mais ser compartilhado.

Karras desafia o demônio a invadir o seu corpo e salva a vida de Regan atirando-se pela janela. Para resgatar a menina de sua condição de "porca" dialogando diretamente com o episódio bíblico, Karras torna-se "porco" e encara a morte. Pulando do segundo andar, rola pela imensa escadaria que conecta à rua a casa dos MacNeil. Neste momento, sentimos a presença da mágica cinematográfica quando, por um fugaz segundo, a câmera mergulha para fora do quarto e vemos a palavra "porcos" grafitada na parede. Karras derrota o demônio transformando-se, ele próprio, em sujeito demonizado. A jornada do monstro animal encerra quando o exorcista possuído compreende que precisa aniquilar o duplo para restituir a ordem familiar, que não admite ambivalência. Porém, a própria caracterização do demônio como animal (seja figurado como Pazuzu ou como Regan possuída) é ambivalente: ao mesmo tempo em que o monstro animal provoca repulsa e temor, ele permanece familiar ao olhar humano. O animal é a face reconhecível do medo e o reconhecimento é o primeiro passo para a elaboração estratégica do ataque. Contrariando o padre 
Merrin, acredito que a animalidade do possuído não serve para nos afrontar e sim para oferecer uma via de redenção do horror sobrenatural. O humano espectral está fora da nossa compreensão, mas o bicho é nosso velho conhecido. Em outras palavras, Jesus sacrifica os porcos, mas salva o homem.

\section{O horror doméstico como punição para a mulher independente}

Os filmes Carrie
Brian De Palma Rosemary's Baby (Roman Polanski, 1968) e It's Alive! (Larry Cohen, 1974) são bons exemplos de versões terroríficas de eventos cruciais na vida de uma mulher: a primeira menstruação, a gravidez e o parto.

4 Assim como Van Helsing e seus companheiros exterminando Lucy morta-viva, os exorcistas se apoiam na religião para regular e conter a sexualidade do feminino abjeto. A transformação de Regan de criança angelical para monstro violento funciona como uma espécie de chamado para o heroísmo masculino: quando a mulher se torna um "isso", "uma coisa"', é hora de destruir o dragão e salvar a donzela. Biskind aponta que a "sexualidade feminina é comparada a possessão demoníaca e os homens no filme - quase todos padres celibatários - se unem (...) para recuperar a sua inocência sexual" (Easy Riders, Raging Bulls, p. 217).

5 O autor David J. Skal analisou a problemática geracional de $O$ Exorcista: "O filme se tornou um ritual cultural altamente divulgado de exorcismo não do demônio, mas dos confusos sentimentos parentais de culpa e responsabilidade na era do Vietnã quando - sob uma perspectiva conservadora - crianças desbocadas estavam tomando drogas que afetavam a sua personalidade e agindo de forma agressiva, em suma, tornando a vida dos adultos bastante desagradável". (David J. Skal, The Monster Show (New York: Faber \& Faber,1993, p.295).
O feminino monstruoso é um dos constructos mais recorrentes nas narrativas de horror. Percebidas como animalescas uma vez tocadas pelo mal, as mulheres-monstro habitam um território limítrofe entre humanidade e animalidade.

$\mathrm{O}$ horror gerado pela fêmea monstruosa tende a expor o atordoamento vivenciado pela mulher quando confrontada com mudanças importantes em suas vidas - e em seus corpos também. ${ }^{3}$ Peter Biskind classificou O Exorcista, junto com Carrie, a Estranha, deStephen King, no que chama de "pânico menstrual". (BISKIND, 1998, p.217) Prefiro abordá-lo como "pânico pubescente" e ampliar o conceito de modo a acomodar concepções híbridas de estágios fronteiriços, como os lobisomens adolescentes ou donzelas vampirizadas. ${ }^{4}$

A menina Regan, quando possuída pelo demônio, reproduz de maneira hiperbólica a inquieta rebeldia da adolescência. ${ }^{5}$ Como adolescente insurgente sob jugo demoníaco, ela ataca família, religião e ciência com o mesmo desprezo, direcionando golpes verbais e físicos contra a mãe, os padres e os médicos. Ela também encena, com recorrente linguagem chula e gestos obscenos, uma fixação púbere com o sexo. A famosa cena na qual se masturba com um crucifixo e esfrega o rosto da mãe em sua vagina ensanguentada permanece o auge definitivo do feminino abjeto no cinema de horror: herético, incestuoso e sexualmente agressivo.

Se por um lado temos um retrato explícito da pré-adolescente subversiva e fora de controle, por outro temos, implicitamente, o da mãe como responsável pelo comportamento violento da filha. Em O Exorcista, a ausência materna é sugerida como causa da transformação monstruosa tanto no romance quanto no filme. Instabilidade mental, doença e morte são associadas à negligência familiar em uma construção perversa que termina por vincular possessão demoníaca à independência de Chris MacNeil, a mãe de Regan. O corpo da criança invadido pelo mal é interpretado como um resultado da solidão e carência da menina, provocadas pela rotina profissional da mãe. Como filha única de uma celebridade divorciada, Regan é frequentemente deixada aos cuidados da criadagem da casa e passa muitas horas sozinha no porão, fazendo esculturas de animais e brincando de contatar espíritos com uma tábua Ouija. Embora a ligação não seja explicitada nesses termos, livro e filme sugerem que o passaporte do demônio para o corpo 


\footnotetext{
6 É curioso observar como filmes mais recentes de possessão seguem a mesma regra. Em Possessão, de Ole Bornedal (2012), o casal divorciado Clyde e Stephanie são de certa forma punidos pela separação quando sua filha caçula, Emma, compra uma caixa $d y b b u k$ em uma venda de garagem e fica possuída por um demônio chamado Abyzou ("o raptor de crianças"). Lendo nas mudanças comportamentais da menina uma reação natural ao divórcio, o casal não percebe os primeiros sinais de sua mudança, desconsiderando qualquer aspecto sobrenatural. No fim, trabalhando unida, a família consegue libertar Emma do demônio e marido e mulher se reconciliam. A última cena do filme mostra a família tomando café da manhã na cozinha, um clichê de felicidade conjugal no cinema norte-americano.
}

de Regan foi a busca da própria por interlocução. No silêncio deixado pelos pais, Regan encontrou diálogo com o demônio. Para Biskind, "Satã é o pai malvado que se aloja na residência da divorciada MacNeil no lugar do pai-marido ausente." (BISKIND, 1998, p.217, trad. livre) Esta leitura controversa da possessão estabelece um vínculo perigoso entre a carreira bem-sucedida da mãe e a vulnerabilidade da filha, propensa a doenças psicossomáticas. $\mathrm{O}$ vínculo é ainda mais evidente no romance, quando a enfermidade misteriosa de Regan obriga Chris a abandonar a oportunidade, há muito desejada, de dirigir um filme. $\mathrm{O}$ deslocamento da mulher como atriz (funcionária, submissa, passiva, decorativa) para diretora (chefe, autônoma, ativa, intelectual) é contido por uma energia masculina falocêntrica materializada não apenas no corpo da filha violado pelo demônio, mas também na súbita e providencial presença de médicos e padres como agentes de interdição. $O$ autor Barry Keith Grant afirma: “a possessão demoníaca da filha é consequência de a mãe ter colocado a sua carreira acima da família" (GRANT, 2004, p.166, trad. livre) O próprio demônio, falando através de Regan, acusa Chris em um trecho que revela, talvez mais do que qualquer outro, a formação católica do autor (cabe observar que as únicas palavras que ganharam ênfase, no roteiro original, foram "marido" e "divórcio":

Regan/Demon:
Ah, a mãe da pequena suína! Vem, vem ver a sua obra, porca! Veja o vômito! Veja a cadela assassina! Está satisfeita? A culpa é toda sua! Sim, foi você quem colocou a carreira acima dela, acima do seu marido, acima de tudo! O divórcio é a causa disso tudo! Vá procurar padres, vá! Os padres não vão lhe ajudar! Ela é louca! Você a transformou em uma louca assassina! Você cavou a sepultura dela! (BLATTY, 2000, p.133, trad. livre)

Assim, o demônio prontamente reestabelece as prioridades da mãe, transformando Chris de estrela de cinema em dona de casa. É como se ela estivesse sendo punida por todas as soireés no tapete vermelho, pelas capas de revistas e sua crescente reputação como uma 'atriz séria'. Dos jantares na Casa Branca para os lençóis fétidos de Regan, parece que a mãe está finalmente onde as narrativas conservadoras de horror gostariam que ela estivesse: em casa.

As ficções que gravitam em torno de crianças demoníacas podem ser interpretadas como contos admonitórios dirigidos a futuros pais, como advertência aos perigos de reproduções não-convencionais e/ou configurações familiares transgressoras da norma. ${ }^{6} \mathrm{O}$ horror doméstico como punição normalmente sugere que a mulher é a culpada pelas consequências de um filho amaldiçoado - até mesmo quando a mãe permanece o alvo principal dos ataques. 


\section{O monstro como psicopompo}

Em $O$ Exorcista a animalidade do corpo possuído evoca a duplicidade do próprio ser humano. A figura de Pazuzu exibida no filme reprisa o gesto de Hermes, apontando para cima e para baixo ao mesmo tempo. Tal gesto sintetiza o conceito de reciprocidade de ações, aproximando polaridades em um reflexo especular que garante: nenhum fenômeno é isolado ou carece de complementação. $\mathrm{O}$ confronto com o lado sombrio pressupõe um afastamento temporário das certezas racionais que ancoram a visão cientificista da mãe de Regan, por exemplo, levando-a a suspender o seu ateísmo em prol de uma esperança de fé. Simbolizado por Pazuzu e pela própria Regan possuída, o animal em $O$ Exorcista preserva a sua liminaridade, sendo, simultaneamente, familiar e estranho. Ao mesmo tempo em que o corpo a-humano provoca desconforto, ele oferece pistas de reconhecimento, o que o torna menos invencível. Ao entender que a estratégia do demônio é animalizar Regan até que ela perca a sua humanidade, os exorcistas conseguem abstrair o espetáculo da possessão, neutralizando o temor que ela inspira. Uma vez detectado o animal na menina, o exorcismo se torna um adestramento, uma domesticação.

Animalidade e os limites da domesticação permanecem questões pouco compreendidas. Empenhados em domesticar o monstro animal, encantadores de cães e exorcistas ficcionais viram-se não apenas abraçando os seus instintos, mas tornando-se mais vulneráveis a experiências de empatia radical. Técnicas do gênero 'Pense como um animal' e o sacrifício derradeiro do padre Karras tornam mais indistinta a linha que separa a fronteira homem-animal, aproximando heróis e monstros para um território comum. O exorcista possuído pelo demônio é uma figura poderosa: como curador-ferido, ele não pode salvar a si mesmo, mas não obstante, consegue derrotar o mal. O sacrifício de Karras, coadunando-se com a construção messiânica do personagem, funciona como um expurgo, um ato de amor altruísta tão contundente que põe fim à trama. A destruição do bode-expiatório restaura a paz e reaquece a fé, mas também prova que a morte é a única via segura para dissipar a desconfortável coexistência do homem com o animal no mesmo corpo. Karras não comete suicídio; ele aniquila a besta na qual se tornou. Ao fazê-lo, reconhece o animal não apenas como um adversário de respeito, mas como um provável vencedor.

Faz parte da história humana adorar e temer o animal e, embora uma viscosa aderência à racionalidade estrita tenha nos separado do mundo natural (levando-nos até a esquecer que somos natureza), as figuras animais sobrevivem graças a nossa necessidade constante do seu poder simbólico. O monstro animal permite uma reavaliação da nossa animalidade reprimida, em busca de um escape mais saudável para os nossos medos do que 
o reino escuro da intolerância. Somente aceitando a nossa natureza bestial, seremos capazes de vivenciar a nossa humanidade por completo.

Talvez, no dia em que aceitarmos as nossas próprias cabeças de cachorro e caudas de escorpião, Pazuzu será apenas um lembrete de que o verdadeiro demônio é a ignorância.

\begin{abstract}
This article analyses the function of animal traits in the transformation from human to monster in the movie "The Exorcist", based on the homonymous best-seller by William Peter Blatty. Released in 1973, it remains one of the most disturbing accomplishments of Horror cinema and stands as a seminal work of the demonic movie subgenre. The Horror narrative describes a journey in which the animal, by virtue of its ubiquitous presence in our lives, frequently acts as a psychopomp. Although the depiction of animality as a mark of villainy has been detrimental to our perception of some animals, it has nevertheless contributed to an ongoing reflection about the human-animal relationship. Horror narratives remain the main locus of animality in works of fiction, for their unrivalled ability to gather archetypical representations and to invite us to experience a vicarious confrontation with our own repressed fears. The article proposes a reflection on animality as a path to reintegration of the Self, defending the endurance of animal monsters in the Horror genre.
\end{abstract}

Keywords: animality; monstrosity; domestication; psychopomp.

\title{
REFERÊNCIAS
}

ARNZEN, Michael A., "There is Only One”: The Restoration of the Repressed in The Exorcist: The Version You've Never Seen. In: The Exorcist: Studies in the Horror Film, ed. Daniel Olson. Colorado: Centipede Press, 2011, p. 349-374.

. Familial Ideology in The Exorcist. In: The Exorcist: Studies in the Horror Film, ed. Daniel Olson. Colorado: Centipede Press, 2011, p. 261-274.

BISKIND, Peter. Easy Riders, Raging Bulls: How the Sex-Drugs-andRock 'n' Roll Generation Saved Hollywood. New York: Simon \& Schuster, 1998. 
BLATTY, William Peter. The Exorcist: 40th Anniversary Edition. New York: Harper Collins, 2011. Ed. Kindle.

The Exorcist - the script. London: Faber and Faber, 2000.

BRIGHT, Michael. Beasts of The Field: The Revealing Natural History of Animals in the Bible. London: Robson Books, 2006.

GRANT, Barry Keith. Rich and Strange: The Yuppie Horror Film. In: ed. Planks of Reason: Essays on Horror Film. Oxford: The Scarecrow Press, 2004, p. 153- 170.

KEY, Wilson Bryan. Media Sexploitation: The Hidden Implants in America's Mass Media - and how they program and condition your subconscious mind. New York: Signet, 1977.

SHEVWLOW, Kathryn. For the Love of Animals: The Rise of the Animal Protection Movement. New York: Holt Paperbacks, 2008. SKAL, David J. The Monster Show: A Cultural History of Horror. New York: Faber \& Faber, 1993. 